Article

\title{
Estimation of Diurnal Cycle of Land Surface Temperature at High Temporal and Spatial Resolution from Clear-Sky MODIS Data
}

\author{
Si-Bo Duan ${ }^{1,2}$, Zhao-Liang Li ${ }^{3,4, *}$, Bo-Hui Tang ${ }^{1}$, Hua Wu ${ }^{1}$, Ronglin Tang ${ }^{1}$, Yuyun Bi ${ }^{3}$ \\ and Guoqing Zhou ${ }^{5}$
}

1 State Key Laboratory of Resources and Environment Information System, Institute of Geographic Sciences and Natural Resources Research, Chinese Academy of Sciences, Beijing 100101, China; E-Mails: duansibo@gmail.com (S.D.); tangbh@igsnrr.ac.cn (B.T.); wuhua@igsnrr.ac.cn (H.W.); trl_wd@163.com (R.T.)

2 University of Chinese Academy of Sciences, Beijing 100049, China

3 Key Laboratory of Agri-Informatics, Ministry of Agriculture/Institute of Agricultural Resources and Regional Planning, Chinese Academy of Agricultural Sciences, Beijing 100081, China;

E-Mail: biyuyun@caas.cn

4 ICube, UdS, CNRS, 300 Bld Sebastien Brant, CS10413, F-67412 Illkirch, France

5 Guangxi Key Laboratory of Spatial Information and Geomatics, Guilin University of Technology, Guangxi 541004, China; E-Mail: gzhou@glut.edu.cn

* Author to whom correspondence should be addressed; E-Mail: lizhaoliang@caas.cn; Tel.: +86-10-8210-5077.

Received: 3 March 2014; in revised form: 2 April 2014 / Accepted: 4 April 2014 /

Published: 10 April 2014

\begin{abstract}
The diurnal cycle of land surface temperature (LST) is an important element of the climate system. Geostationary satellites can provide the diurnal cycle of LST with low spatial resolution and incomplete global coverage, which limits its applications in some studies. In this study, we propose a method to estimate the diurnal cycle of LST at high temporal and spatial resolution from clear-sky MODIS data. This method was evaluated using the MSG-SEVIRI-derived LSTs. The results indicate that this method fits the diurnal cycle of LST well, with root mean square error (RMSE) values less than $1 \mathrm{~K}$ for most pixels. Because MODIS provides at most four observations per day at a given location, this method was further evaluated using only four MSG-SEVIRI-derived LSTs corresponding to the MODIS overpass times (10:30, 13:30, 22:30, and 01:30 local solar time). The results show that the RMSE values using only four MSG-SEVIRI-derived LSTs are approximately two
\end{abstract}


times larger than those using all LSTs. The spatial distribution of the modeled LSTs at the MODIS pixel scale is presented from 07:00 to 05:00 local solar time of the next day with an increment of 2 hours. The diurnal cycle of the modeled LSTs describes the temporal evolution of the LSTs at the MODIS pixel scale.

Keywords: land surface temperature (LST); diurnal temperature cycle (DTC); MODIS; MSG-SEVIRI

\section{Introduction}

Land surface temperature (LST) and its diurnal variation are crucial for the physical processes of land surface energy and water balance at regional and global scales [1-6]. The diurnal cycle of LST is closely related to solar insolation, the state of the atmosphere, and surface characteristics, e.g., soil type, soil moisture, and vegetation cover [7]. Satellite remote sensing provides the unique way to measure the diurnal cycle of LST over extended regions [8-10].

The diurnal cycle of LST has been used for a wide variety of applications. For example, the diurnal cycle of LST was used to analyze the urban thermal environment [11-14]. In addition, the diurnal cycle of LST was used to normalize the satellite-derived LSTs at different times to the same time $[15,16]$. Jin and Treadon [17] used the diurnal cycle of LST to correct the orbit drift effects on the National Oceanic and Atmospheric Administration (NOAA) Advanced Very-High-Resolution Radiometer (AVHRR) LST measurements. Schroedter-Homscheidt et al. [18] retrieved total water vapor column from Meteosat Second Generation -Spinning Enhanced Visible and Infrared Imager (MSG-SEVIRI) data with the aid of the diurnal cycle of LST.

Geostationary satellites with high temporal resolution have become increasingly attractive for their ability to fully characterize the diurnal cycle of LST. However, the diurnal cycle of LST with low spatial resolution (e.g., $3 \mathrm{~km}$ at nadir for MSG-SEVIRI) and incomplete global coverage limits its applications in some studies, e.g., urban heat island [14]. Compared with geostationary satellite data, polar-orbiting satellite data (e.g., MODIS and NOAA-AVHRR) have high spatial resolution of approximately $1 \mathrm{~km}$ at nadir. Therefore, various methods have been developed to estimate the diurnal cycle of LST at high temporal and spatial resolution from polar-orbiting satellite measurements. Jin and Dickinson [19] estimated the diurnal cycle of LST by interpolating NOAA-AVHRR twice-per-day measurements into the typical patterns of the diurnal cycle of LST, which were derived from climate models. Sun and Pinker [20] performed work similar to that of Jin and Dickinson [19], but the typical patterns of the diurnal cycle of LST were derived from Geostationary Operational Environmental Satellite (GOES) measurements. Inamdar et al. [21] developed an algorithm to disaggregate the diurnal cycle of LST at the GOES pixel scale to that at the MODIS pixel scale. Zhou et al. [14] used a diurnal temperature cycle generic algorithm to estimate the diurnal cycle of LST at the MODIS pixel scale with the aid of the diurnal cycle of the FY-2C-derived LST.

The methods described above can be used to estimate the diurnal cycle of LST at high temporal and spatial resolution from polar-orbiting satellite measurements. Nevertheless, these methods require the typical patterns of the diurnal cycle of LST, which are derived from climate models or geostationary 
satellite measurements. Therefore, a simple and straightforward method for estimating the diurnal cycle of LST at high temporal and spatial resolution only using polar-orbiting satellite data is needed. The objective of this study is to develop a method to estimate the diurnal cycle of LST at high and spatial resolution only using MODIS LST measurements. This paper is organized as follows: Section 2 describes the study area and the data used in this study. Section 3 describes the method for estimating the diurnal cycle of LST from MODIS LST measurements. The results and discussion are presented in Section 4. Conclusions are presented in the last section.

\section{Study Area and Data}

\subsection{Study Area}

The study area is located in the Mediterranean region with longitude from $15^{\circ} \mathrm{W}$ to $15^{\circ} \mathrm{E}$ and latitude from $30^{\circ} \mathrm{N}$ to $48^{\circ} \mathrm{N}$. This area has a Mediterranean climate, with mild, rainy winters and hot, dry summers. The land cover types of the study area generated from the Collections 5.1 MODIS land cover type product MCD12Q1 are shown in Figure 1. To match the MSG-SEVIRI pixels, the MCD12Q1 pixels were aggregated to the MSG-SEVIRI pixel scale in terms of longitude and latitude. Only six general land cover classes over land at the MSG-SEVIRI pixel scale are displayed in Figure 1. This area is mainly dominated by unvegetated land, cropland, and shrubland.

Figure 1. Land cover types of the study area at the MSG-SEVIRI pixel scale aggregated from the Collection 5.1 MODIS land cover type product MCD12Q1. Six selected pixels over different land cover types were used to evaluate the performance of the 4-parameter diurnal temperature cycle (DTC) model.

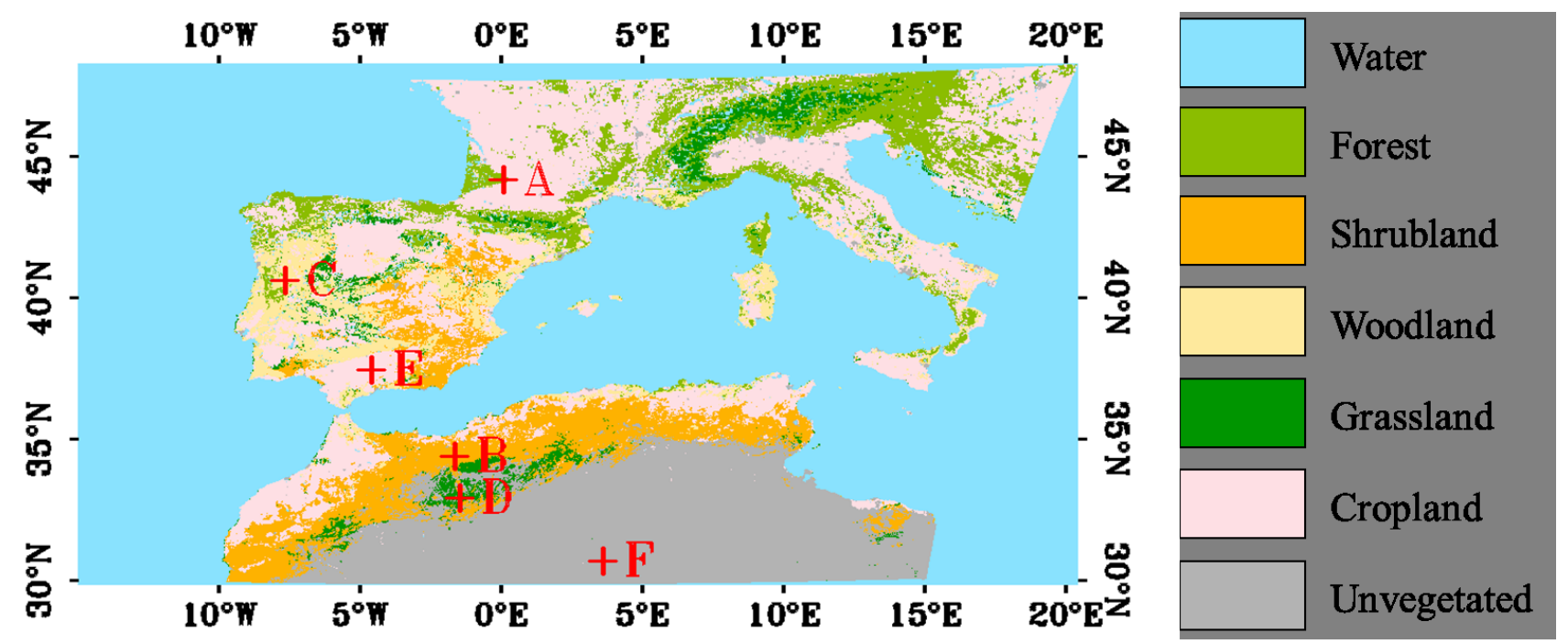

\subsection{MSG-SEVIRI Data}

The level-1.5 image and cloud mask products were downloaded from the European Organization for the Exploitation of Meteorological Satellites (EUMETSAT) Earth Observation Portal (EOP) website (https://eoportal.eumetsat.int/). The level-1.5 image data were converted into the top-of-the-atmosphere (TOA) brightness temperatures of MSG-SEVIRI channels $9(10.8 \mu \mathrm{m})$ and $10(12.0 \mu \mathrm{m})$ using the 
SEVIRI Pre-processing Toolbox (SPT) software. The LST retrieval algorithms [22,23] were used to derive LST from the TOA brightness temperatures of MSG-SEVIRI channels 9 and 10. Only the pixels identified as clear sky over land in the cloud mask product were used in this study. To evaluate the performance of the proposed method, MSG-SEVIRI data on 28 January, 9 April, 31 July, and 1 October 2010 were used in this study. These four days are the days with the most cloud-free pixels in January, April, July, and October 2010, which represent four seasons of the year.

\subsection{MODIS Data}

The MODIS/Terra and MODIS/Aqua Land Surface Temperature and Emissivity Daily L3 Global 1-km SIN Grid products (MOD11A1 and MYD11A1, Collection 5) downloaded from the Reverb website (http://reverb.echo.nasa.gov/) were used in this study. The MOD11A1 and MYD11A1 products provide per-pixel LST and emissivity values at $1-\mathrm{km}$ resolution using the generalized split-window algorithm [24]. LST, observation time (local solar time), and quality control (QC) were extracted from the MOD11A1 and MYD11A1 products. Only the pixels flagged as good quality (i.e., QC $=0$ ) were used in this study.

\section{Methodology}

Inamdar et al. [21] developed a two-part, semi-empirical diurnal temperature cycle (DTC) model to describe the diurnal variations of LST. This DTC model uses a cosine function to predict the evolution of the daytime LST and a hyperbolic function to describe the decay of the LST at night. Duan et al. [25] improved this DTC model by deducing the width $\omega$ over the half-period of the cosine term from the thermal diffusion equation. This model is described as:

$$
\begin{aligned}
& T_{s}^{d}(t)=T_{0}+T_{a} \cos \left(\frac{\pi}{\omega}\left(t-t_{\mathrm{m}}\right)\right), t<t_{s} \\
& T_{s}^{n}(t)=T_{0}+\delta T+\left[T_{a} \cos \left(\frac{\pi}{\omega}\left(t_{s}-t_{\mathrm{m}}\right)\right)-\delta T\right] \frac{k}{\left(k+t-t_{s}\right)}, \quad t \geq t_{s}
\end{aligned}
$$

with

$$
\begin{gathered}
k=\frac{\omega}{\pi}\left[\tan ^{-1}\left(\frac{\pi}{\omega}\left(t_{s}-t_{\mathrm{m}}\right)\right)-\frac{\delta T}{T_{a}} \sin ^{-1}\left(\frac{\pi}{\omega}\left(t_{s}-t_{\mathrm{m}}\right)\right)\right] \\
\omega=\frac{4}{3}\left(t_{\mathrm{m}}-t_{s r}\right)
\end{gathered}
$$

All of the meanings of the parameters in the DTC model are illustrated in Figure 2, where $T_{S}^{d}$ and $T_{S}^{n}$ are the LSTs of the daytime and night-time parts, respectively, $t$ is the time, $T_{0}$ is the residual temperature around sunrise, $T_{\mathrm{a}}$ is the temperature amplitude, $\omega$ is the width over the half-period of the cosine term, $t_{\mathrm{m}}$ is the time at which the temperature reaches its maximum, $t_{\mathrm{sr}}$ is the time of sunrise, $t_{\mathrm{s}}$ is the start time of free attenuation, $\delta T$ is the temperature difference between $T_{0}$ and $T(t \rightarrow \infty)$, and $k$ is the attenuation constant.

There are five free parameters in the DTC model, i.e., $T_{0}, T_{\mathrm{a}}, \delta T, t_{\mathrm{m}}$, and $t_{\mathrm{s}}$. Nevertheless, MODIS provides at most four observations per day at a given location. To fit the DTC model to MODIS four observations, at least one of the five DTC model parameters requires to be known as a priori knowledge 
or as a constraint to the DTC model. Statistical analyses indicate that $t_{\mathrm{s}}$ is approximate to be 1 hour before the time of sunset $\left(t_{\mathrm{ss}}\right)$, which can be seen from Figure 2. Fixing $t_{\mathrm{s}}$ at 1 hour before $t_{\mathrm{ss}}$ cannot introduce large error into the DTC model, which will illustrate in Section 4.1. We assume that the value of $t_{\mathrm{s}}$ is approximately equal to the value of $t_{\mathrm{ss}}-1$. Therefore, there are only four free parameters in the DTC model, i.e., $T_{0}, T_{\mathrm{a}}, \delta T$, and $t_{\mathrm{m}} . \omega$ and $k$ are calculated using Equations (2) and (3), respectively. $t_{\mathrm{sr}}$ and $t_{\mathrm{ss}}$ are calculated from solar geometry. In this study, the DTC model with $t_{\mathrm{s}}$ treated as a free parameter is referred to as the 5-parameter model; and the DTC model with $t_{\mathrm{s}}$ estimated from $t_{\mathrm{ss}}-1$ is called the 4-parameter model.

Figure 2. Illustration of the DTC model parameters. $T_{s}^{d}$ and $T_{s}^{n}$ are the land surface temperatures (LSTs) of the daytime and night-time parts, respectively, $t$ is the time, $T_{0}$ is the residual temperature around sunrise, $T_{\mathrm{a}}$ is the temperature amplitude, $\omega$ is the width over the half-period of the cosine term, $t_{\mathrm{m}}$ is the time at which the temperature reaches its maximum, $t_{\mathrm{sr}}$ is the time of sunrise, $t_{\mathrm{ss}}$ is the time of sunset, $t_{\mathrm{s}}$ is the start time of free attenuation, $\delta T$ is the temperature difference between $T_{0}$ and $T(t \rightarrow \infty)$, and $k$ is the attenuation constant.

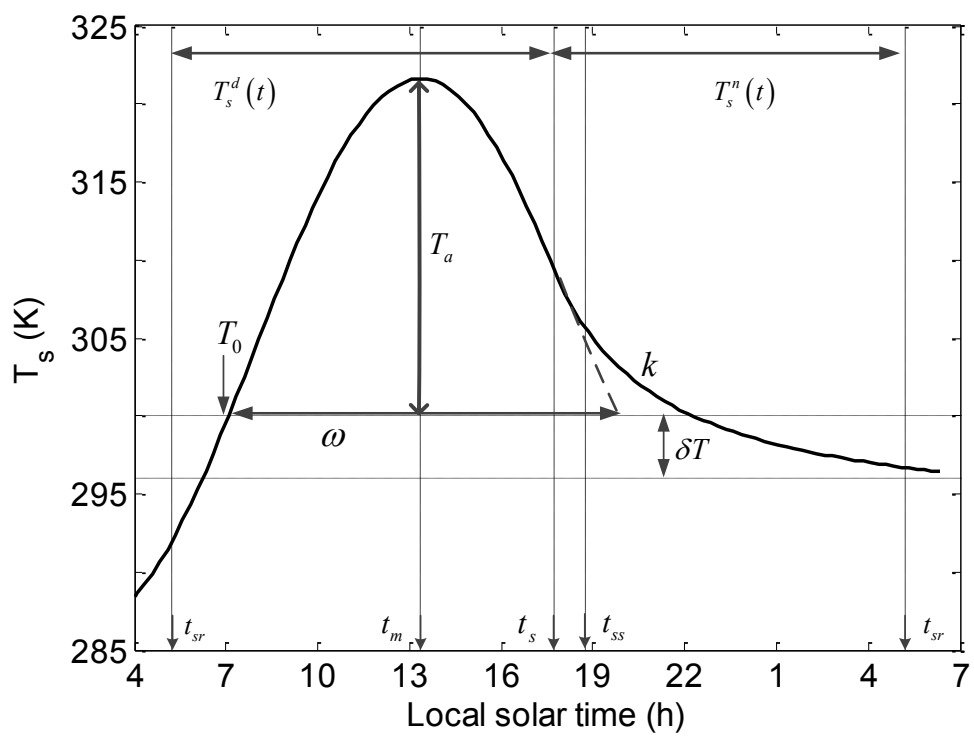

One should keep in mind that (1) these two models have been developed under clear-sky conditions without significant changes in wind speed; (2) these two models assume the temperature decays freely after "thermal sunset" at time $t_{\mathrm{s}}$; and (3) these two models cannot be used with satellite observations less than four times for each day, which is the case encountered in many regions of the world.

\section{Results and Discussion}

\subsection{Evaluation of the 4-parameter DTC Model}

Before evaluating the performance of the 4-parameter DTC model, we compared the values of $t_{\mathrm{s}}$ obtained from model fitting (i.e., $t_{\mathrm{s}}$ treated as a free parameter) and those of $t_{\mathrm{s}}$ estimated from $t_{\mathrm{ss}}-1$. Histograms of the differences between $t_{\mathrm{s}}$ obtained from model fitting and $t_{\mathrm{s}}$ estimated from $t_{\mathrm{ss}}-1$ for all cloud-free pixels on 28 January, 9 April, 31 July, and 1 October 2010 are shown in Figure 3. The root 
mean square error (RMSE) values of the $t_{\mathrm{s}}$ differences are $0.76 \mathrm{~h}, 0.87 \mathrm{~h}, 1.05 \mathrm{~h}$, and $0.40 \mathrm{~h}$ on 28 January, 9 April, 31 July, and 1 October 2010, respectively.

Figure 3. Histograms of the differences between $t_{\mathrm{s}}$ obtained from model fitting (i.e., $t_{\mathrm{s}}$ treated as a free parameter) and $t_{\mathrm{s}}$ estimated from $t_{\mathrm{ss}}-1$ for all cloud-free pixels on (a) 28 January, (b) 9 April, (c) 31 July, and (d) 1 October 2010.
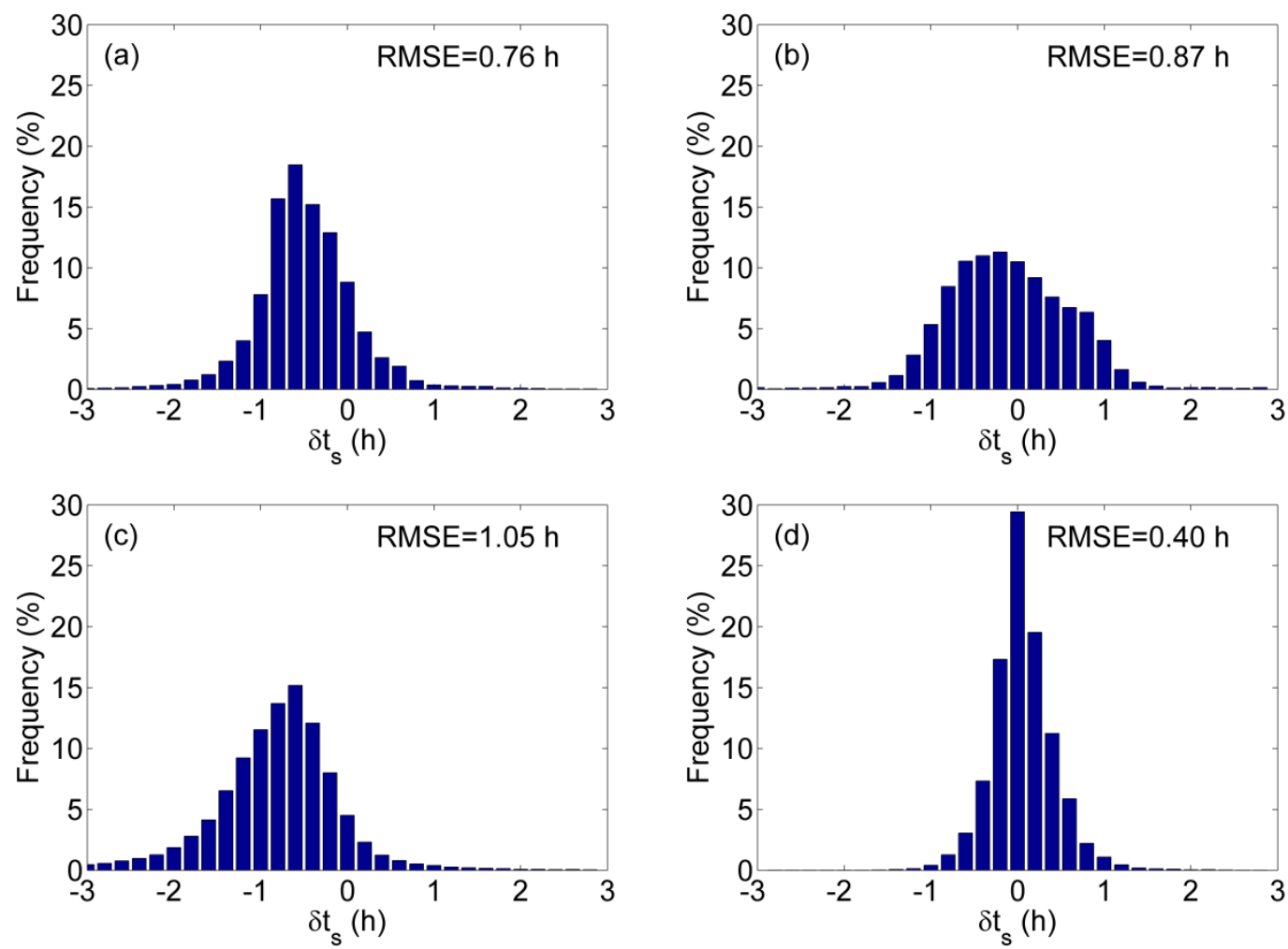

As an example, six pixels over different land cover types on 31 July 2010 were selected to evaluate the performance of the 4-parameter DTC model. The location of the six selected pixels is shown in Figure 1 and summarized in Table 1. The 4-parameter DTC model was used to fit the diurnal cycle of the MSG-SEVIRI-derived LST over the six selected pixels. To avoid the influences of the previous night-time cooling and of the next day solar heating on the fitting of LST [26,27], the diurnal cycle of the MSG-SEVIRI-derived LST from 2 hour after sunrise to 1 hour before sunrise of the following day were used in this study. The fitting results are shown in Figure 4. The RMSE values of the fitting errors are $0.21 \mathrm{~K}, 0.31 \mathrm{~K}, 0.32 \mathrm{~K}, 0.43 \mathrm{~K}, 0.39 \mathrm{~K}$, and $0.50 \mathrm{~K}$ for forest, shrubland, woodland, grassland, cropland, and unvegetated land, respectively.

Table 1. Detailed information of the six selected pixels.

\begin{tabular}{lllll}
\hline Site & Latitude & Longitude & Elevation & Land Cover Type \\
\hline A & $43.909^{\circ} \mathrm{N}$ & $0.235^{\circ} \mathrm{E}$ & $153.1 \mathrm{~m}$ & Forest \\
B & $34.161^{\circ} \mathrm{N}$ & $1.677^{\circ} \mathrm{W}$ & $1134.2 \mathrm{~m}$ & Shrubland \\
$\mathrm{C}$ & $40.030^{\circ} \mathrm{N}$ & $7.166^{\circ} \mathrm{W}$ & $381.7 \mathrm{~m}$ & Woodland \\
$\mathrm{D}$ & $33.941^{\circ} \mathrm{N}$ & $0.769^{\circ} \mathrm{W}$ & $1080.4 \mathrm{~m}$ & Grassland \\
$\mathrm{E}$ & $37.405^{\circ} \mathrm{N}$ & $4.326^{\circ} \mathrm{W}$ & $746.2 \mathrm{~m}$ & Cropland \\
$\mathrm{F}$ & $30.642^{\circ} \mathrm{N}$ & $3.564^{\circ} \mathrm{E}$ & $347.6 \mathrm{~m}$ & Unvegetated \\
\hline
\end{tabular}


Figure 4. Fitting the 4-parameter DTC model to the diurnal cycle of the MSG-SEVIRI-derived LST on 31 July 2010 for the six selected pixels over different land cover types: (a) forest, (b) shrubland, (c) woodland, (d) grassland, (e) cropland, and (f) unvegetated land. Fitting errors of LST are also shown.
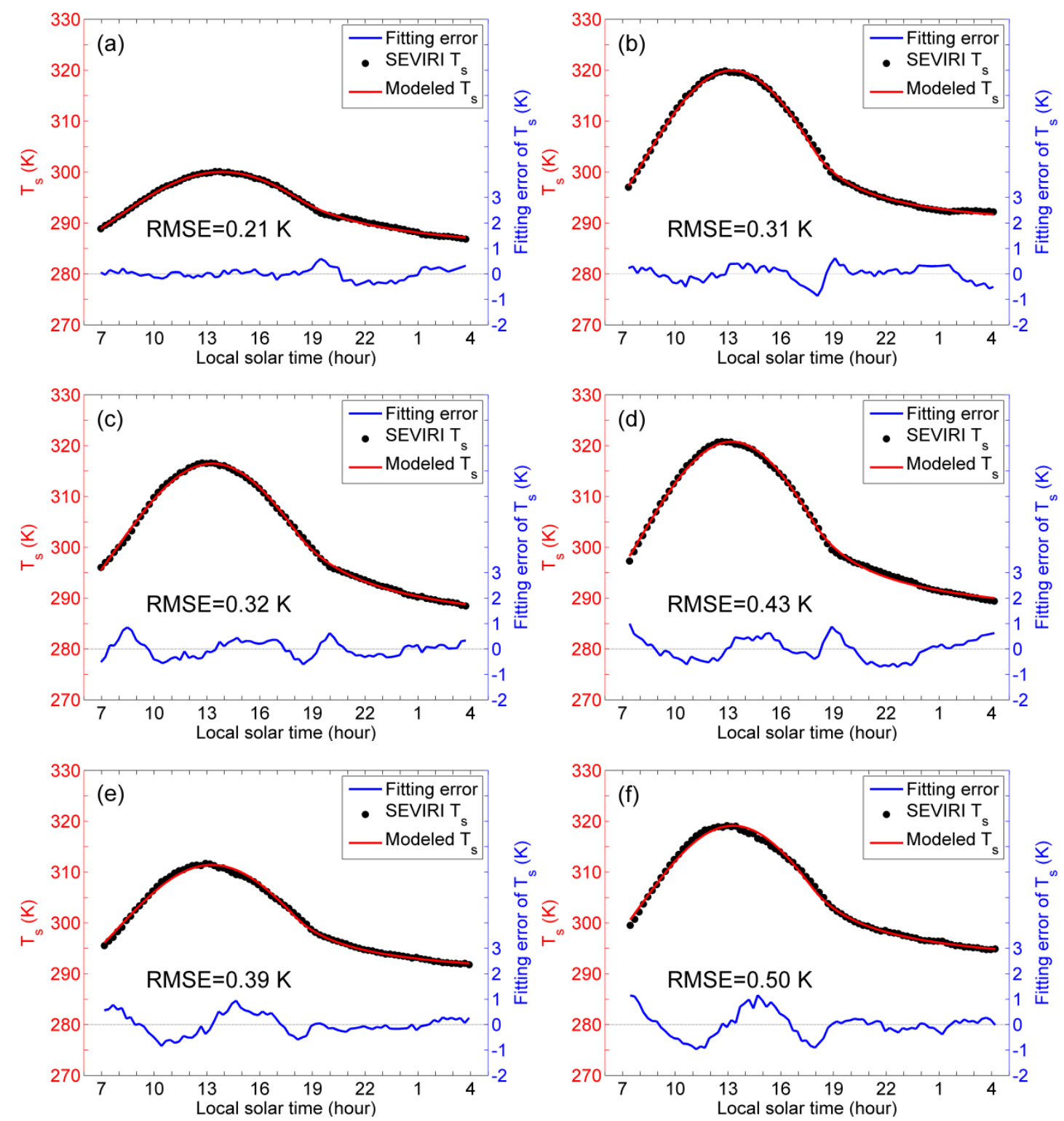

We used all cloud-free pixels on 28 January, 9 April, 31 July, and 1 October 2010 to statistically evaluate the performance of the 4-parameter DTC model. Figure 5 shows the histograms of the RMSE values of the 4-parameter DTC model fitting the diurnal cycle of the MSG-SEVIRI-derived LST on these four days. The fitting accuracy of the 4-parameter model is achieved with RMSE values less than $1 \mathrm{~K}$ for most pixels. The performance of the 4-parameter model depends on the quality of LST as well as on atmospheric and surface-wind conditions.

To compare the performance of the 5-parameter DTC model (i.e., the DTC model with $t_{\mathrm{s}}$ treated as a free parameter) and the 4-parameter DTC model (i.e., the DTC model with $t_{\mathrm{s}}$ estimated from $t_{\mathrm{ss}}-1$ ), all cloud-free pixels on 28 January, 9 April, 31 July, and 1 October 2010 were used in this study. The histograms of the RMSE values of the 5-parameter DTC model fitting the diurnal cycle of the 
MSG-SEVIRI-derived on these four days are shown in Figure 6. The fitting accuracy of the 5-parameter DTC model is also achieved with RMSE values less than $1 \mathrm{~K}$ for most pixels. Comparing Figure 5 with Figure 6, the fitting accuracy of the 4-parameter DTC model is slightly less than that of the 5-parameter DTC model. These results demonstrate that fixing $t_{\mathrm{s}}$ at $t_{\mathrm{ss}}-1$ has no significant influences on the fitting accuracies of the 4-parameter DTC model.

Figure 5. Histograms of the RMSE values of the 4-parameter DTC model fitting the diurnal cycle of the MSG-SEVIRI-derived LST for all cloud-free pixels on (a) 28 January, (b) 9 April, (c) 31 July, and (d) 1 October 2010.
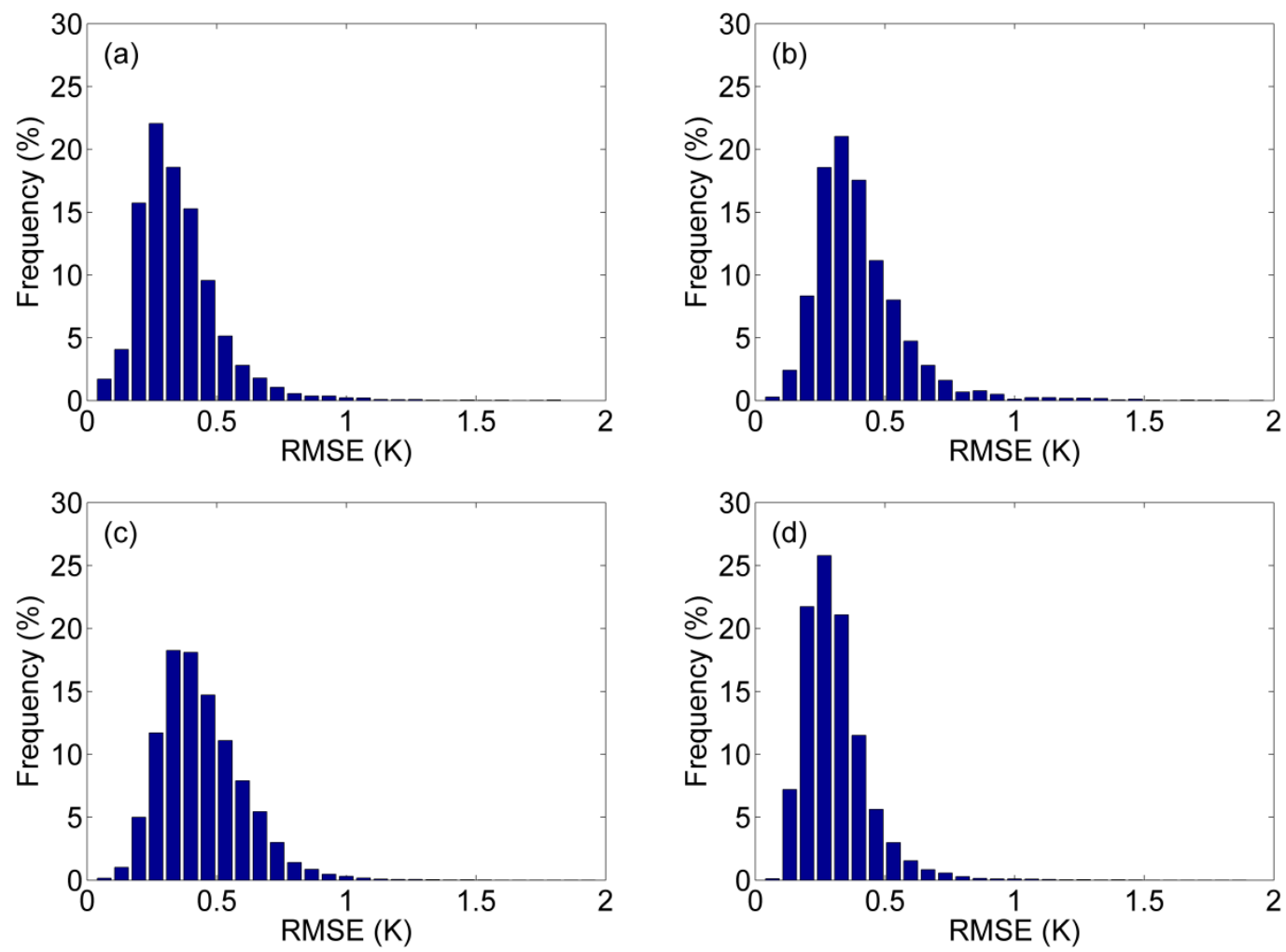

Figure 6. Histograms of the RMSE values of the 5-parameter DTC model fitting the diurnal cycle of the MSG-SEVIRI-derived LST for all cloud-free pixels on (a) 28 January, (b) 9 April, (c) 31 July, and (d) 1 October 2010.
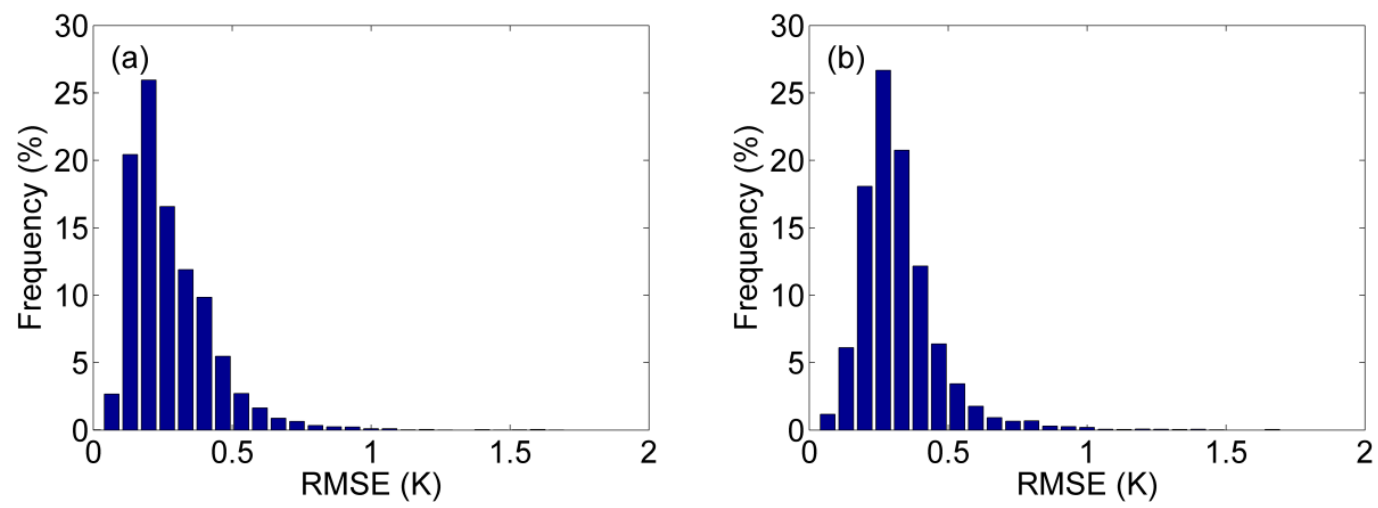
Figure 6. Cont.
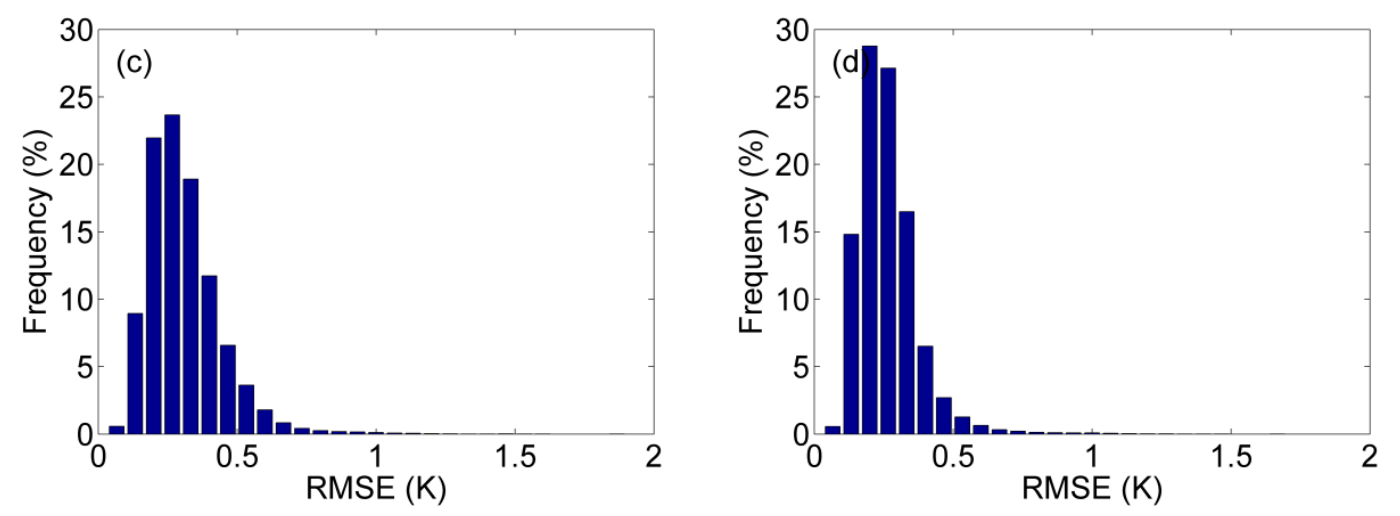

\subsection{Fitting the 4-Parameter DTC Model to Four Observations}

As mentioned previously, MODIS provides at most four observations per day at a given location. We assume that only four MSG-SEVIRI-derived LSTs corresponding to the MODIS overpass times (10:30, 13:30, 22:30, and 01:30 local solar time) for each day are available. The remaining MSG-SEVIRI-derived LSTs were used to evaluate the performance of the 4-parameter DTC model fitting only four observations. The fitting results over the six selected pixels (see Table 1) on 31 July 2010 are shown in Figure 7. The RMSE values of the fitting errors are $0.57 \mathrm{~K}, 0.66 \mathrm{~K}, 0.66 \mathrm{~K}, 0.91 \mathrm{~K}, 0.79 \mathrm{~K}$, and $0.75 \mathrm{~K}$ for forest, shrubland, woodland, grassland, cropland, and unvegetated land, respectively. Comparing Figure 7 with Figure 4, the RMSE values using only four LSTs are approximately two times larger than those using all LSTs. Relatively larger fitting errors can be observed between approximately 18:00 and 21:00 local solar time (see Figure 7a,c,d) as well as the periods before 09:00 local solar time (see Figure 7d-f), due to the lack of LST measurements over these periods.

Figure 7. Fitting the 4-parameter DTC model to only four MSG-SEVIRI-derived LSTs on 31 July 2010 for the six selected pixels over different land cover types: (a) forest, (b) shrubland, (c) woodland, (d) grassland, (e) cropland, and (f) unvegetated land. Fitting errors of LST are also shown. Filled squares represent the LSTs corresponding to the MODIS overpass times (10:30, 13:30, 22:30, and 01:30 local solar time).
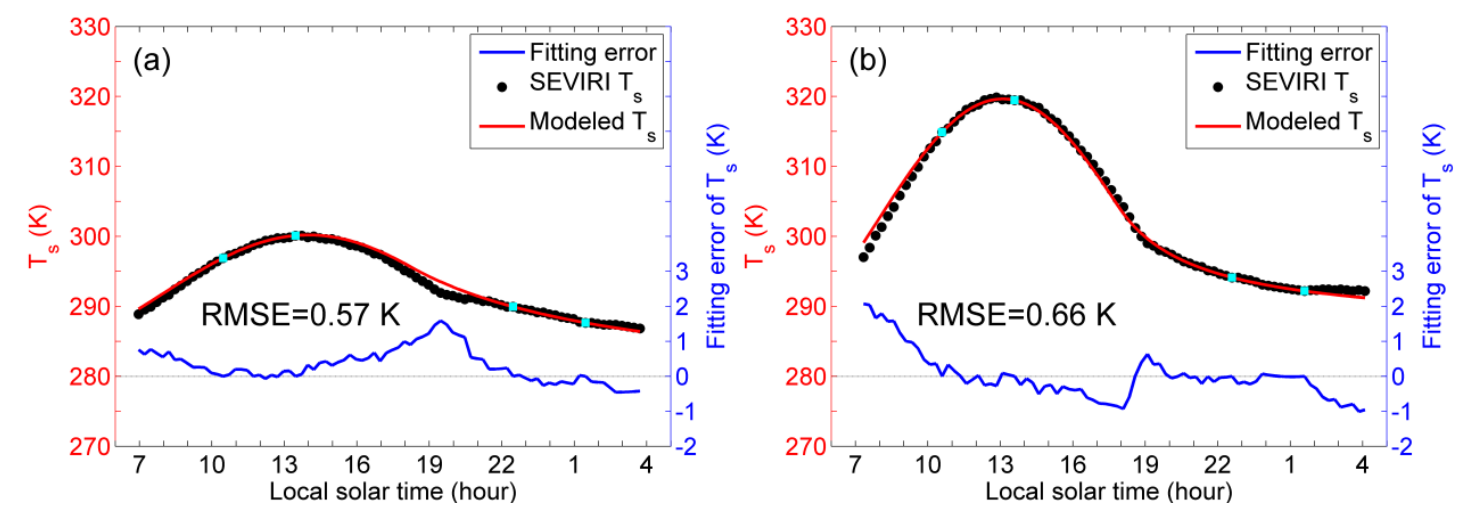
Figure 7. Cont.
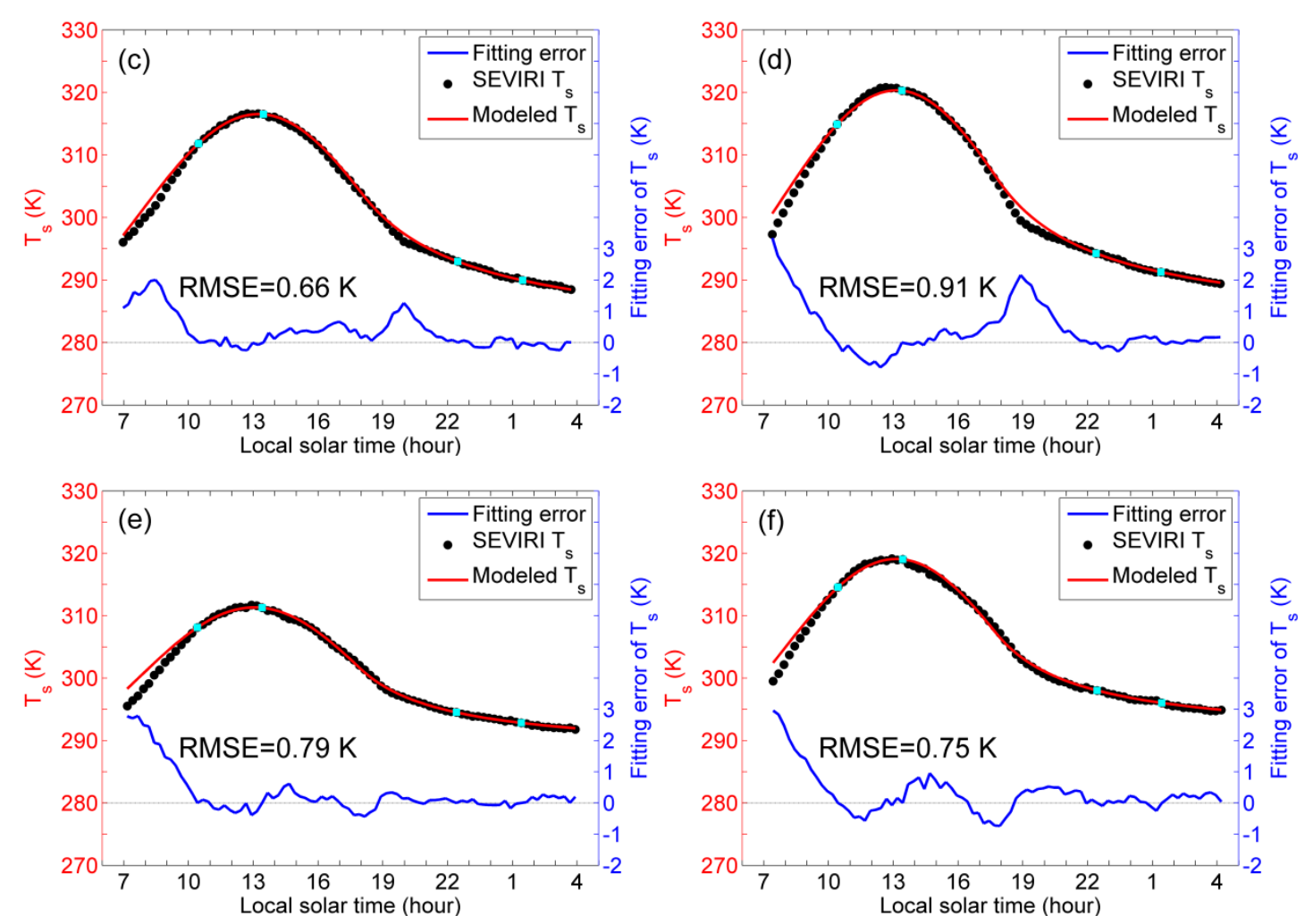

All cloud-free pixels on 28 January, 9 April, 31 July, and 1 October 2010 were used to statistically analyze the RMSE values of the 4-parameter DTC model fitting only four LSTs. Histograms of the RMSE values on these four days are shown in Figure 8. The RMSE values of the 4-parameter DTC model fitting only four MSG-SEVIRI-derived LSTs are less than $2 \mathrm{~K}$ for most pixels. Comparing Figure 8 with Figure 5, the RMSE values using only four LSTs are approximately two times larger than those using all LSTs.

Figure 8. Histograms of the RMSE values of the 4-parameter DTC model fitting only four MSG-SEVIRI-derived LSTs for all cloud-free pixels on (a) 28 January, (b) 9 April, (c) 31 July, and (d) 1 October 2010.
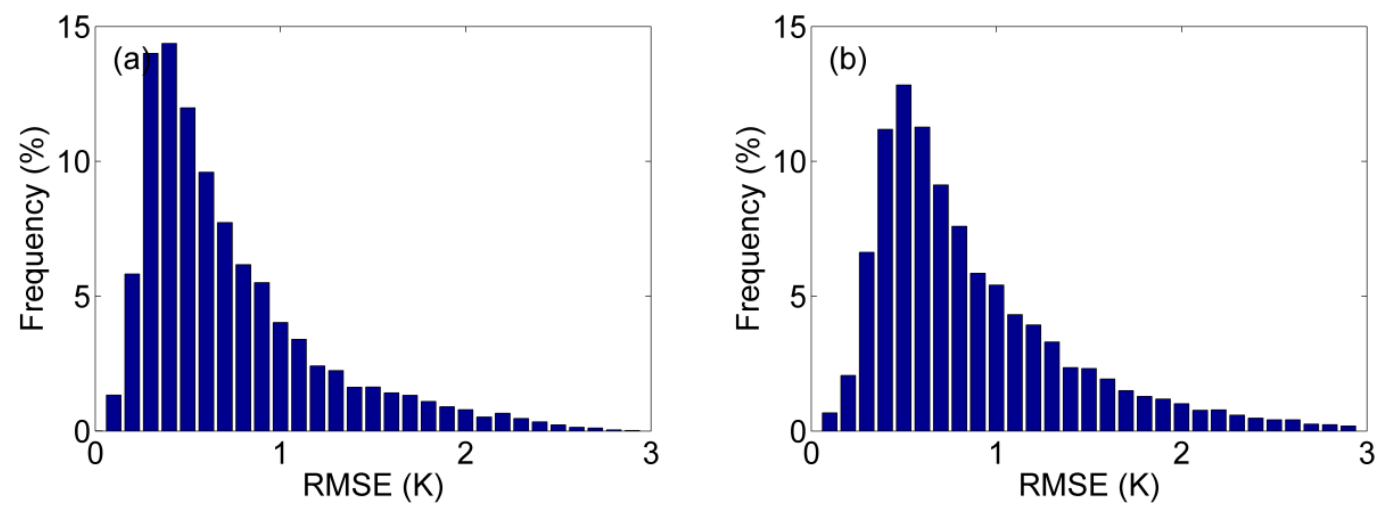
Figure 8. Cont.
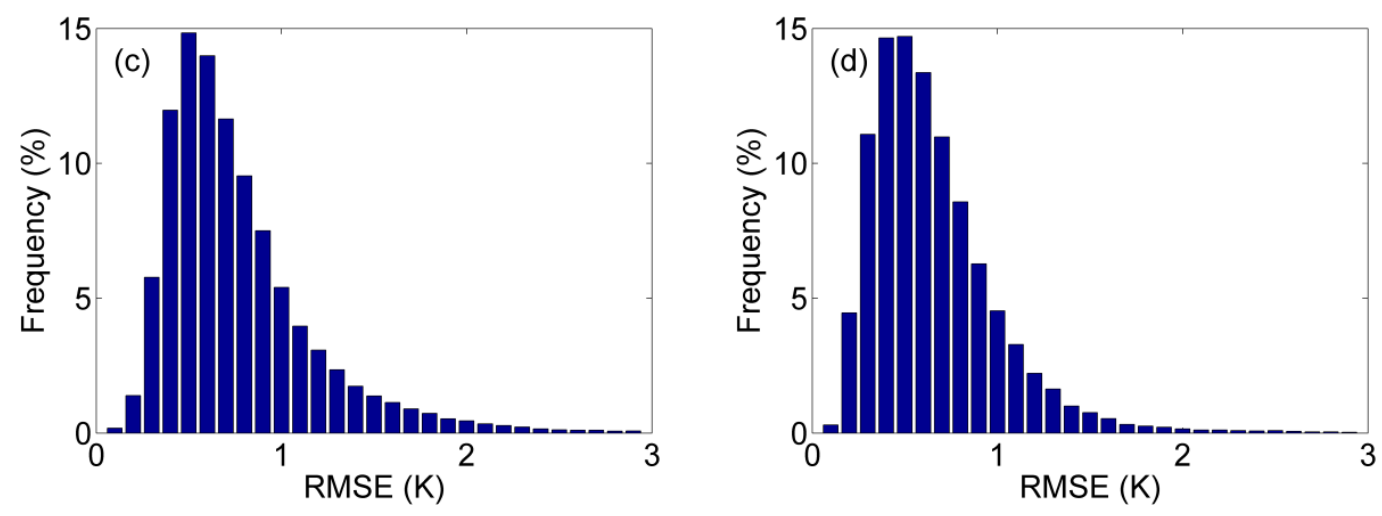

\subsection{Application to MODIS Data}

The 4-parameter DTC model was used to fit four MODIS LSTs for each day (MOD11A1 and MYD11A1, daytime and night-time). As an example, the diurnal cycle of LST at the MODIS pixel scale over the six selected pixels (see Table 1) on 31 July 2010 is shown in Figure 9. The accuracy of the modeled LSTs depends on those of the four MODIS LSTs. Fitting the 4-parameter DTC model to the LSTs with errors may lead to large errors on the modeled LSTs due to numerical computation.

Figure 9. Fitting the 4-parameter DTC model to four MODIS LSTs (filled squares) on 31 July 2010 for the six selected pixels over different land cover types: (a) forest, (b) shrubland, (c) woodland, (d) grassland, (e) cropland, and (f) unvegetated land.
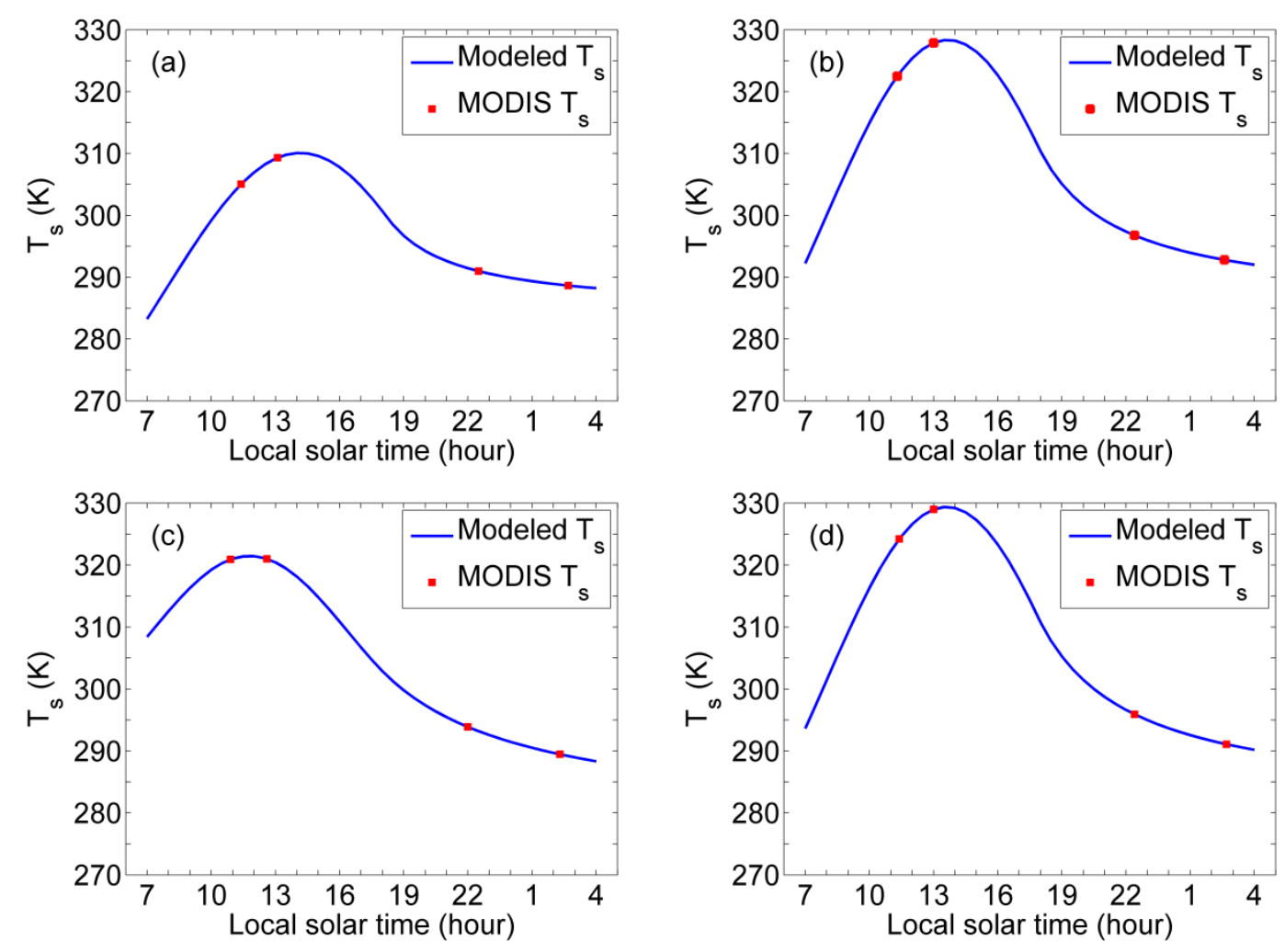
Figure 9. Cont.
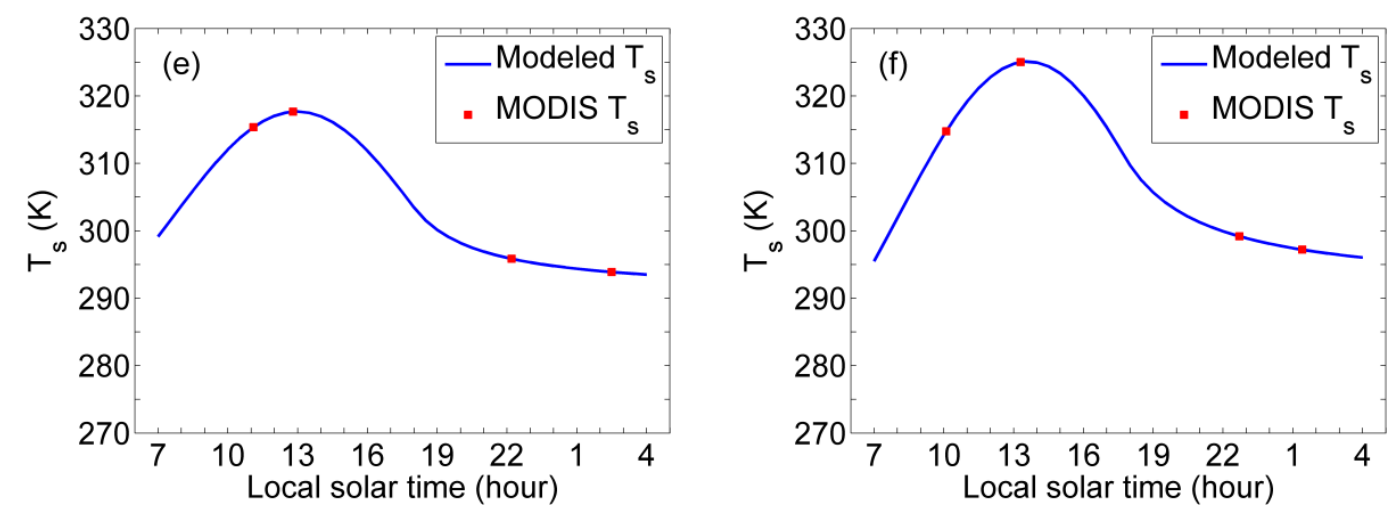

The modeled LSTs are not validated due to the lack of in situ measurements or remotely sensed data from another source. Validation of LST at the satellite pixel scale is challenging because LST can vary significantly within a pixel and change within relatively short time periods [28]. In theory, the four MODIS LSTs should be normalized to the same view angle (e.g., at nadir) before fitting the 4-parameter DTC model to the four MODIS LSTs. Although the directional effects (angular anisotropy) in the LST have been demonstrated at the satellite pixel scale [29-32], there is not any practical way to perform angular normalization of satellite-derived LST, because of the complexity of this normalization.

An area covered by the MODIS sinusoidal tile H17V05 was selected as an example to display the spatial distribution of the modeled LSTs at the MODIS pixel scale. We modeled the LSTs spanning from 07:00 to 05:00 local solar time of the next day with an increment of $2 \mathrm{~h}$. The LSTs between 05:00 and 07:00 local solar time of the next day were not modeled due to large model error over these periods. The modeled LSTs are shown in Figure 10. These maps describe the temporal evolution of the LSTs at the MODIS pixel scale.

Figure 10. Spatial distribution of the modeled LSTs at the MODIS pixel scale spanning from 07:00 to 05:00 local solar time of the next day with an increment of $2 \mathrm{~h}$.
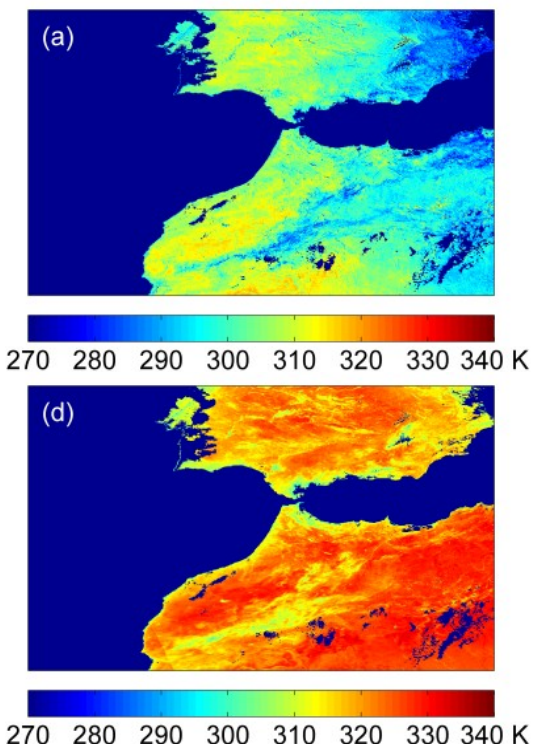
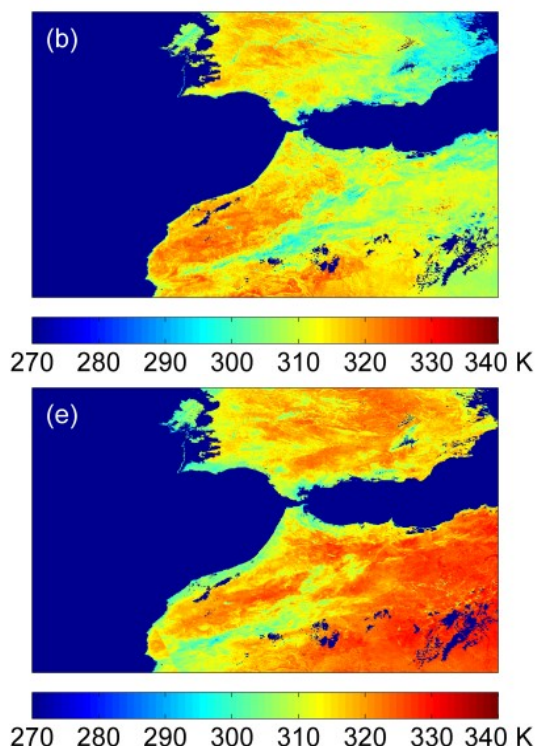
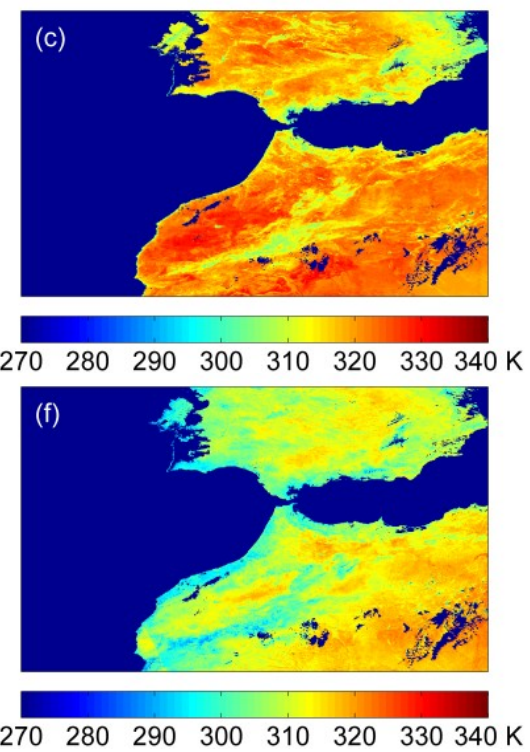
Figure 10. Cont.
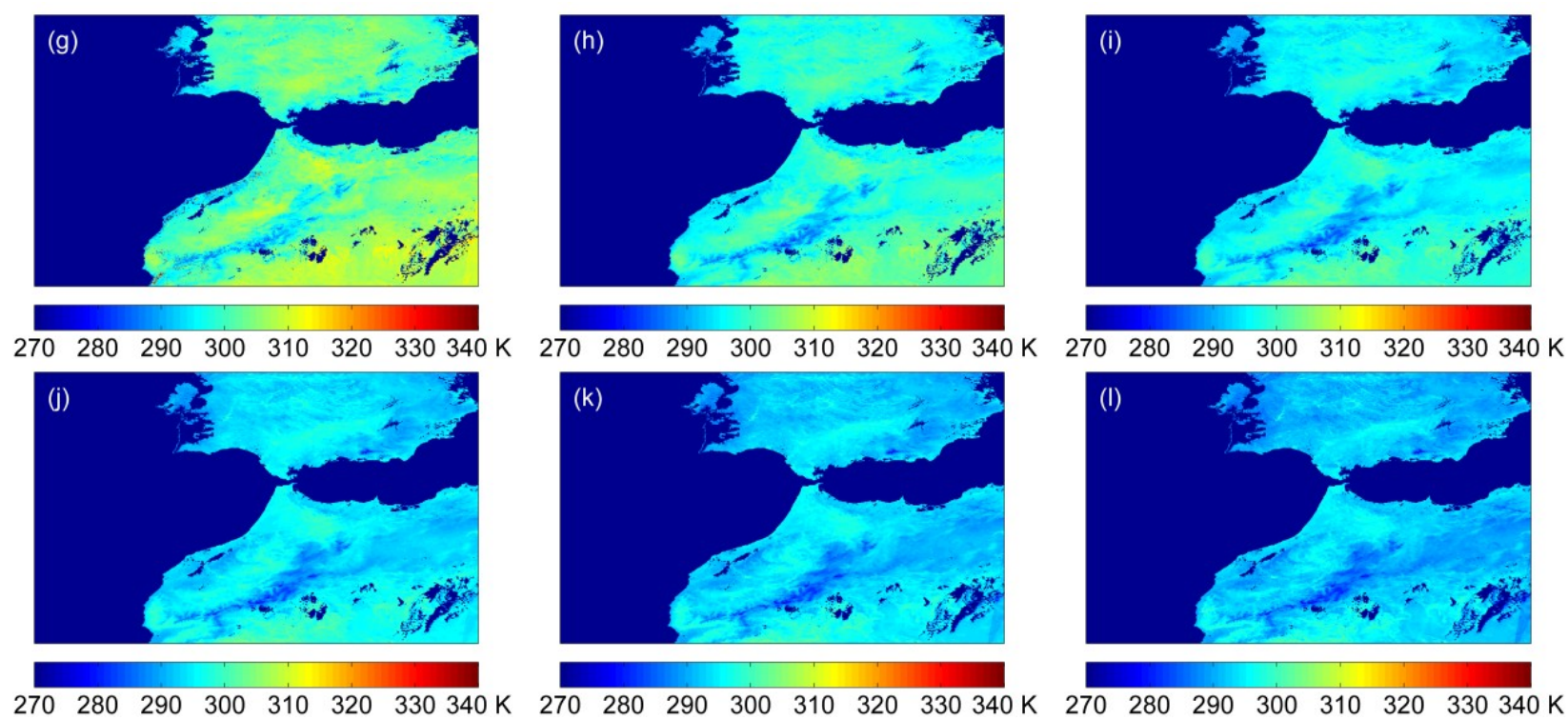

\section{Conclusions}

Assuming that the start time of free attenuation $t_{\mathrm{s}}$ can be fixed at $1 \mathrm{~h}$ before the time of sunset $t_{\mathrm{ss}}$, a 4-parameter diurnal temperature cycle (DTC) model was presented to estimate the diurnal cycle of land surface temperature (LST) at high temporal and spatial resolution from clear-sky MODIS LST measurements. The values of $t_{\mathrm{s}}$ estimated from $t_{\mathrm{ss}}-1$ were compared with those of $t_{\mathrm{s}}$ obtained from model fitting (i.e., $t_{\mathrm{s}}$ treated as a free parameter). The results indicate that the root mean squared error (RMSE) values of the $t_{\mathrm{s}}$ differences are less than $1.1 \mathrm{~h}$. Because MSG-SEVIRI can provide thermal infrared data every $15 \mathrm{~min}$, the diurnal cycle of the MSG-SEVIRI-derived LST was used to evaluate the performance of the 4-parameter DTC model. The results show that the 4-parameter DTC model fits the diurnal cycle of the MSG-SEVIRI-derived LST well, with RMSE values less than $1 \mathrm{~K}$ for most pixels. We compared the performance of the 5-parameter DTC model (i.e., the DTC model with $t_{\mathrm{s}}$ treated as a free parameter) and the 4-parameter DTC model. The results indicate that the performance of the 4-parameter DTC model is comparable with that of the 5-parameter DTC model.

Because MODIS provides at most four observations per day at a given location, the 4-parameter DTC model was used to fit only four MSG-SEVIRI-derived LSTs corresponding to the MODIS overpass times (10:30, 13:30, 22:30, and 01:30 local solar time). The remaining LSTs were used to evaluate the accuracies of the 4-parameter DTC model fitting only four observations. The results show that the accuracies of the 4-parameter DTC model fitting only four MSG-SEVIRI-derived LSTs are approximately two times larger than those of the 4-parameter DTC model fitting all LSTs.

The 4-parameter DTC model was applied to fit four MODIS LSTs for each day. The spatial distribution of the modeled LSTs at the MODIS pixel scale is presented from 07:00 to 05:00 local solar time of the next day with an increment of 2 hours. The diurnal cycle of the modeled LSTs describes the temporal evolution of the LSTs at the MODIS pixel scale.

It should be noted that the proposed method can be applied only when four MODIS LSTs (MOD11A1 and MYD11A1, daytime and night-time) per day at a given location are available. Nevertheless, these conditions cannot be met in many cases due to cloud contamination or missing data. 
To obtain the diurnal cycle of LST at the MODIS pixel scale with global coverage, it is necessary to reconstruct the LST before applying the proposed method to the MODIS LSTs. Although several LST reconstruction methods have been developed [33-35], further investigation is still required.

\section{Acknowledgments}

This work was supported by the Chinese 973 Program under Grant 2013CB733402 and by the National Natural Science Foundation of China under Grants 41231170 and 41162011.

\section{Author Contributions}

Si-Bo Duan wrote the manuscript and was responsible for the research design, data preparation and analysis. Zhao-Liang Li, Bo-Hui Tang, and Hua Wu conceived and designed the research. Ronglin Tang, Yuyun Bi, and Guoqing Zhou collected, processed, and analyzed the remotely sensed data.

\section{Conflicts of Interest}

The authors declare no conflict of interest.

\section{References and Notes}

1. Scarino, B.; Minnis, P.; Palikonda, R.; Reichle, R.H.; Morstad, D.; Yost, C.; Shan, B.; Liu, Q. Retrieving clear-sky surface skin temperature for numerical weather prediction application from geostationary satellite data. Remote Sens. 2013, 5, 342-366.

2. Wan, Z.; Li, Z.-L. A physics-based algorithm for retrieving land surface emissivity and temperature from EOS/MODIS data. IEEE Trans. Geosci. Remote Sens. 1997, 35, 980-996.

3. Li, Z.-L.; Tang, R.; Wan, Z.; Bi, Y.; Zhou, C.; Tang, B.; Yan, G.; Zhang, X. A review of current methodologies for regional evapotranspiration estimation from remotely sensed data. Sensors $\mathbf{2 0 0 9}$, 9, 3801-3853.

4. Li, Z.-L.; Tang, B.-H.; Wu, H.; Ren, H.; Yan, G.; Wan, Z.; Trigo, I.F.; Sobrino, J.A. Satellite-derived land surface temperature: Current status and perspectives. Remote Sens. Environ. 2013, 131, 14-37.

5. Cho, A.-R.; Suh, M.-S. Evaluation of land surface temperature operationally retrieved from Korean geostationary satellite (COMS) data. Remote Sens. 2013, 5, 3951-3970.

6. Li, Z.-L.; Wu, H.; Wang, N.; Qiu, S.; Sobrino, J.A.; Wan, Z.; Tang, B.-H.; Yan, G. Land surface emissivity retrieval from satellite data. Int. J. Remote Sens. 2013, 34, 3084-3127.

7. Ignatov, A.; Gutman, G. Monthly mean diurnal cycles in surface temperatures over land for global climate studies. J. Climate 1999, 12, 1900-1910.

8. Aires, F.; Prigent, C.; Rossow, W. Temporal interpolation of global surface skin temperature diurnal cycle over land under clear and cloudy conditions. J. Geophys. Res. 2004, 109, 1-18.

9. Duan, S.-B.; Li, Z.-L.; Wang, N.; Wu, H.; Tang, B.-H. Evaluation of six land-surface diurnal temperature cycle models using clear-sky in situ and satellite data. Remote Sens. Environ. 2012, $124,15-25$. 
10. Duan, S.-B.; Li, Z.-L.; Tang, B.-H.; Wu, H.; Tang, R. Direct estimation of land-surface diurnal temperature cycle model parameters from MSG-SEVIRI brightness temperatures under clear sky conditions. Remote Sens. Environ. 2014, in press.

11. Keramitsoglou, I.; Kiranoudis, C.T.; Weng, Q. Downscaling geostationary land surface temperature imagery for urban analysis. IEEE Geosci. Remote Sens. Lett. 2013, 10, 1253-1257.

12. Zhan, W.; Chen, Y.; Voogt, J.; Zhou, J.; Wang, J.; Liu, W.; Ma, W. Interpolating diurnal surface temperatures of an urban facet using sporadic thermal observations. Build. Environ. 2012, 57, 239-252.

13. Bechtel, B.; Zakšek, K.; Hoshyaripour, G. Downscaling land surface temperature in an urban area: A case study for Hamburg, Germany. Remote Sens. 2012, 4, 3184-3200.

14. Zhou, J.; Chen, Y.; Zhang, X.; Zhan, W. Modelling the diurnal variations of urban heat islands with multi-source satellite data. Int. J. Remote Sens. 2013, 34, 7568-7588.

15. Duan, S.-B.; Li, Z.-L.; Tang, B.-H.; Wu, H.; Tang, R. Generation of a time-consistent land surface temperature product from MODIS data. Remote Sens. Environ. 2014, 140, 339-349.

16. Jiang, G. Retrieval of Land Surface Emissivity and Land Surface Temperature from MSG1-SEVIRI Data. Ph.D. Dissertation, University of Strasbourg, Strasbourg, France, 2007.

17. Jin, M.; Treadon, R.E. Correcting the orbit drift effect on AVHRR land surface skin temperature measurements. Int. J. Remote Sens. 2003, 24, 4543-4558.

18. Schroedter-Homscheidt, M.; Drews, A.; Heise, S. Total water vapour column retrieval from MSG-SEVIRI split window measurements exploiting the daily cycle of land surface temperature. Remote Sens. Environ. 2008, 112, 249-258.

19. Jin, M.; Dickinson, R.E. Interpolation of surface radiative temperature measured from polar orbiting satellites to a diurnal cycle 1. Without clouds. J. Geophys. Res. 1999, 104, 2105-2116.

20. Sun, D.; Pinker, R. Implementation of GOES-based land surface temperature diurnal cycle to AVHRR. Int. J. Remote Sens. 2005, 26, 3975-3984.

21. Inamdar, A.K.; French, A.; Hook, S.; Vaughan, G.; Luckett, W. Land surface temperature retrieval at high spatial and temporal resolutions over the southwestern United States. J. Geophys. Res. 2008, 113, D07107, doi:10.1029/2007JD009048.

22. Jiang, G.; Li, Z.-L. Split-window algorithm for land surface temperature estimation from MSG1-SEVIRI data. Int. J. Remote Sens. 2008, 29, 6067-6074.

23. Jiang, G.; Li, Z.-L.; Nerry, F. Land surface emissivity retrieval from combined mid-infrared and thermal infrared data of MSG-SEVIRI. Remote Sens. Environ. 2006, 105, 326-340.

24. Wan, Z.; Dozier, J. A generalized split-window algorithm for retrieving land-surface temperature from space. IEEE Trans. Geosci. Remote Sens. 1996, 34, 892-905.

25. Duan, S.-B.; Li, Z.-L.; Wu, H.; Tang, B.-H.; Jiang, X.; Zhou, G. Modeling of day-to-day temporal progression of clear-sky land surface temperature. IEEE Geosci. Remote Sens. Lett. 2013, 10, 1050-1054.

26. Göttsche, F.-M.; Olesen, F.-S. Modelling of diurnal cycles of brightness temperature extracted from METEOSAT data. Remote Sens. Environ. 2001, 76, 337-348.

27. Göttsche, F.-M.; Olesen, F.-S. Modelling the effect of optical thickness on diurnal cycles of land surface temperature. Remote Sens. Environ. 2009, 113, 2306-2316. 
28. Frey, C.M.; Kuenzer, C.; Dech, S. Quantitative comparison of the operational NOAA-AVHRR LST product of DLR and the MODIS LST product V005. Int. J. Remote Sens. 2012, 33, 7165-7183.

29. Pinheiro, A.C.T.; Privette, J.L.; Guillevic, P. Modeling the observed angular anisotropy of land surface temperature in a savanna. IEEE Trans. Geosci. Remote Sens. 2006, 44, 1036-1047.

30. Pinheiro, A.C.T.; Privette, J.L.; Mahoney, R.; Tucker, C.J. Directional effects in a daily AVHRR land surface temperature dataset over Africa. IEEE Trans. Geosci. Remote Sens. 2004, 42, 1941-1954.

31. Rasmussen, M.O.; Göttsche, F.-M.; Olesen, F.-S.; Sandholt, I. Directional effects on land surface temperature estimation from Meteosat Second Generation for savanna landscapes. IEEE Trans. Geosci. Remote Sens. 2011, 49, 4458-4468.

32. Rasmussen, M.O.; Pinheiro, A.C.T.; Proud, S.R.; Sandholt, I. Modeling angular dependences in land surface temperature from the SEVIRI instrument onboard the Geostationary Meteosat Second Generation satellites. IEEE Trans. Geosci. Remote Sens. 2010, 48, 3123-3133.

33. Neteler, M. Estimating daily land surface temperature in mountainous environment by reconstructed MODIS LST data. Remote Sens. 2010, 2, 333-351.

34. Ke, L.; Ding, X.; Song, C. Reconstruction of time-series MODIS LST in central Qinghai-Tibet Plateau using geostatistical approach. IEEE Geosci. Remote Sens. Lett. 2013, 10, 1602-1606.

35. Hengl, T.; Heuvelink, G.B.M.; Perčec Tadić, M.; Pebesma, E.J. Spatio-temporal prediction of daily temperatures using time-series of MODIS LST images. Theor. Appl. Climatol. 2012, 107, 265-277.

(C) 2014 by the authors; licensee MDPI, Basel, Switzerland. This article is an open access article distributed under the terms and conditions of the Creative Commons Attribution license (http://creativecommons.org/licenses/by/3.0/). 